Focus: Human-robot interaction and autonomous car interfaces Base:

California College of the Arts, Oakland, CA, and Center of Design Research at Stanford University

\title{
Wendy Ju
}

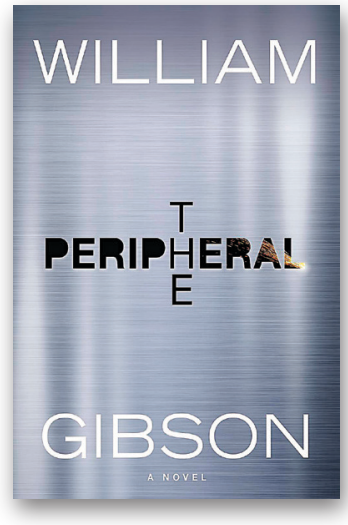

The Peripheral By William Gibson (2014) I love reading William Gibson novels, but
I can't tear through them quickly, like I do regular fiction. Gibson's novels draw a rich and complicated picture of how life might be in the dark cyberpunk future, a future dense with cybernetic implants, shadowy multinational corporations, immersive video games, and killer nanorobots. So many elements in these stories rhyme with the here and now. I find myself trying to unpack a meta-mystery, to figure out what it is in the present day

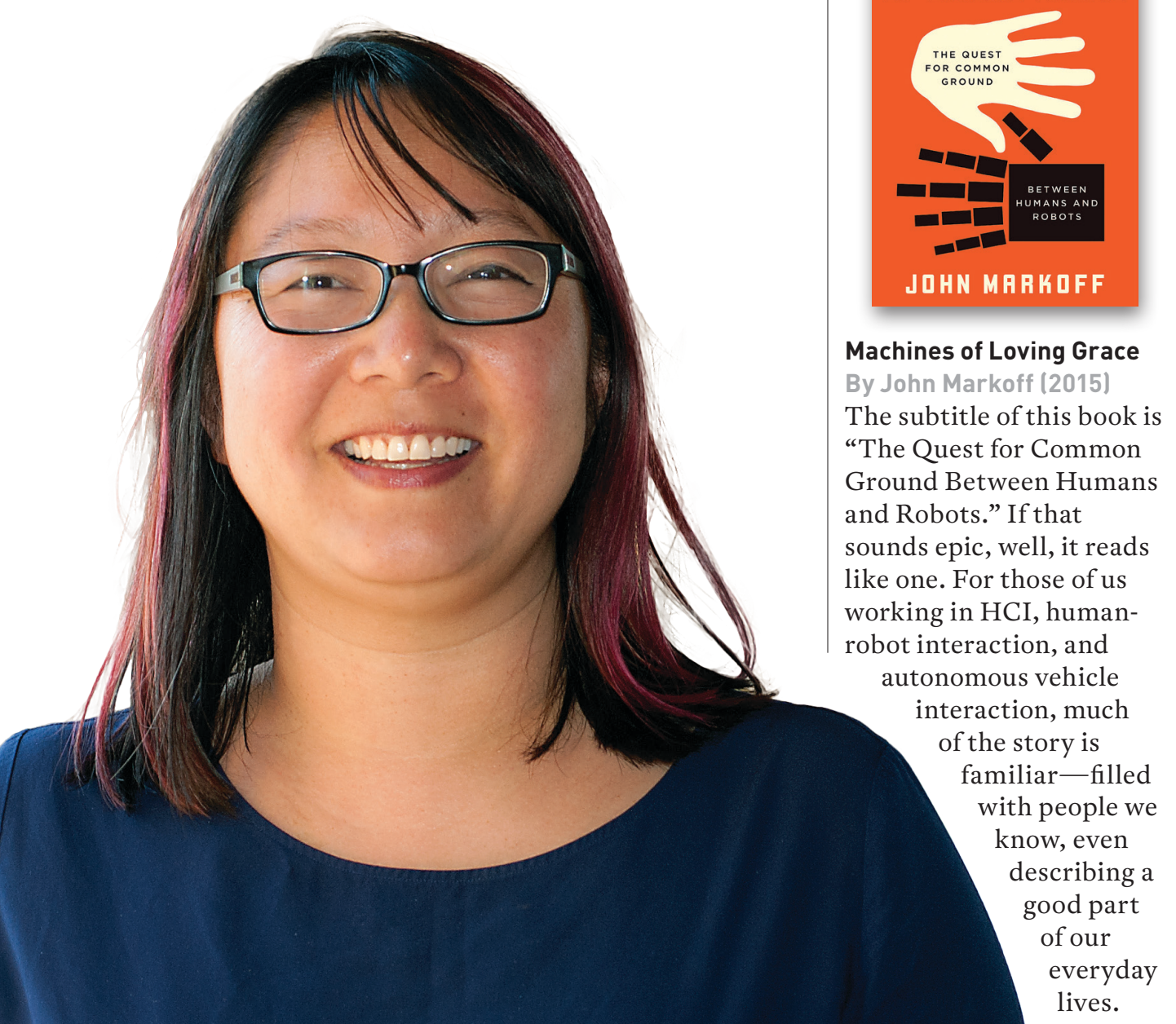

that Gibson is fictionalizing and critiquing in the story. The Peripheral refers to a type of time travel where people from the past can be contacted and can walk about via a physical avatar in the future. The conceit is very relevant to those of us who work in future technologies; imagining the future is a type of time travel, with major implications for the present.

\section{MACHINES DF LOUING GRRCE}

JOHN MARKOF

Machines of Loving Grace By John Markoff (2015)

The subtitle of this book is Qumon

umans sounds epic, well, it reads like one. For those of us working in HCI, humanbot interaction, and miliar-filled ith people we now, even describing good par of our everyd lives.
Still, Markoff's framing of this history as a competition between artificial intelligence and intelligence amplification makes a vivid case for the human element in technology. Perhaps it is good to cultivate the thirdperson perspective on the consequences and import of our work.

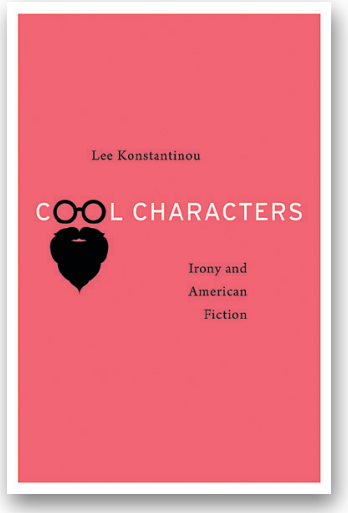

Cool Characters By Lee Konstantinou (2016)

Cool Characters is also a history, of a fictional sort. The book is an examination of irony through the lens of American fiction. It is literary criticism and sometimes dense, but I find it a slow read for the same reasons that reading Gibson is slow. It is impossible for me not to read the traversal from naive belief to irony and cynicism to the postironic without relating it to my own work and practice as an academic researcher. In many ways, I identify with the need to get beyond being cool or clever, to reflect on what I really believe and believe in. 


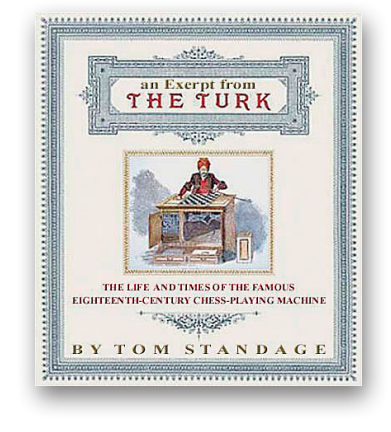

The Turk By Tom Standage (2003) The Turk, which refers to the chess-playing namesake of Amazon's Mechanical Turk, is a fun read about the history of automata up through the age of AI. Because I use a great deal of theater techniques and Wizardof-Oz simulation in my human-robot interaction and autonomous vehicle interaction research, I find the query of where the authenticity lies in a fundamentally artificial experience to be a fascinating one. Are we, like the Turk, performing hoaxes, or is there something more real and important being expressed in the simulacrum?

\footnotetext{
(1) Wendy Ju is an associate professor of design in the California College of the Arts and executive director of interaction design at the Center of Design Research at Stanford University. Her research investigates human interaction with automation, particularly human-robot interaction and autonomous car interfaces.

$\rightarrow$ wendyjudstanford.edu
}

\section{Gibson's novels draw a rich and complicated picture of how life might be in the dark cyberpunk future.}

\section{The VR Book} Human-Centered Design for Virtual Reality

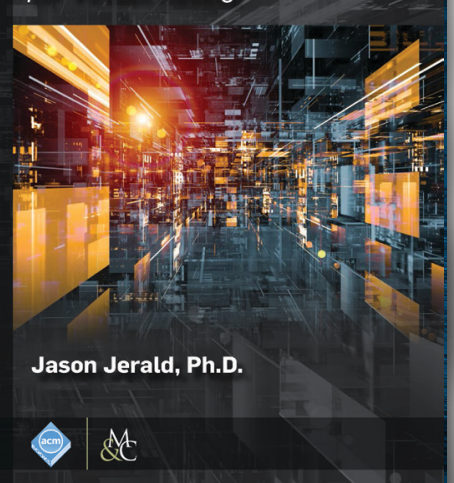

\section{ACM Books.}

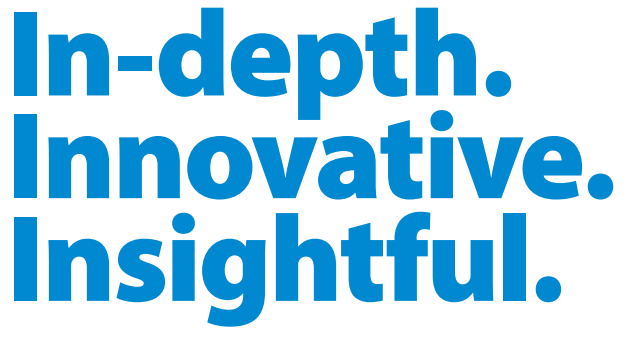

\section{The VR Book: Human-Centered Design for Virtual Reality By Jason Jerald, PhD}

Good VR design requires strong communication between human and machine, indicating what interactions are possible, what is currently occurring, and what is about to occur. A human-centered design principle, like lean methods, is to avoid completely defining the problem at the start and to iterate upon repeated approximations and modifications through rapid tests of ideas with real users. Thus, The VR Book is intended as a foundation for anyone and everyone involved in creating VR experiences including: designers, managers, programmers, artists, psychologists, engineers, students, educators, and user experience professionals.

Available in hardcover, paperback and eBook.

DOI: $10.1145 / 2792790$

For more info please visit http://books.acm.org

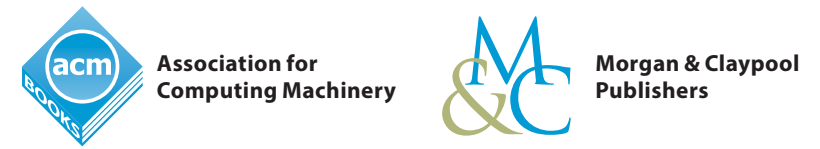

